\title{
The Causes and Solutions Towards the Increasing Locusts Plague in Pakistan
}

\author{
Boyang Tong* \\ Beijing no.2 middle school, Beijing ,100029, China
}

\begin{abstract}
The increasing locusts plague in Pakistan has brought negative impacts on local bio-environment and economy. The plague is expanding toward the nearby nation, if we do not put a stop in it, the plague will destroy the agricultural products in Pakistan, which will lead to a more serious bird declination and deforestation. Besides, a self-reinforcing vicious circle will form, which not only destroy local economy and bio-environment but also threatening the well-being of all nations nearby. Based on data analysis and review of scientific journals on similar fields, the cause of the locusts plague in Pakistan was narrowed to three major aspects: the deforestation resulted from the acid rain, the decline of bird community consequent upon the avian influenza, and the regional temperature increase on account of the wood burning and increasing carbon emission. Therefore, this research will reveal the causes and solutions to the locusts plague in Pakistan and provided people with the valuable experience to prevent it from happening again.
\end{abstract}

\section{Introduction}

Currently, locust plague is sweeping through Pakistan and resulting in a decrease in amounts of crop production. And given that the coronavirus continues to exists, the crops production cannot be revived soon. Therefore, it will cause potential food crisis and economy turmoil in Pakistan. This worst locusts attack for decades has already cut the economical growth of Pakistan to less than $2 \%$ [4]. In addition, the whole country was stuck in inflation [4]. At the same time, the cost of sugar nearly doubling and flour prices jumping 15 per cent in the past year [4]. Apart from the economic disaster, the environmental problem continues to deteriorate. Also, the use of 300 tons pesticides completely disrupted the ecosystem that is already fragile. In this article, detailed, practical solutions will be presented to the three causes of the locusts plague based on published results, data analysis, and circumstances in Pakistan

\section{Argumentation}

\subsection{Deforestation}

Deforestation not only caused the locusts plague but also deteriorated the impacts it brought. The scale of forest in Pakistan has not recovered from the flood of 2010 and it continues to decrease. The progress of deforestation happened in Pakistan mainly through two ways, the acid rain and the expansion of farmland. And those two factors intensified each other to accelerate deforestation.
The acid rain brought by the increasing carbon emission, which was caused by the wood-burning of the farmers [1], jeopardized the land's fertility and made the farmers' land unsuitable for plant economic corps like cotton. Therefore, farmers were forced to expand new lands by cutting down trees. Since there are no longer trees to absorb carbon dioxide in the atmosphere, the carbon emission will increase. In turn, more acid rains will occur Consequently, the expanding farm land accompanied by disappearing forests will cause more detrimental effects for economy. Because of the lack in protection and the block of forests, more farmlands will be exposed to locusts and cause higher economic loss. The measurement of local governments to prevent deforestation includes REDD + program, the social safeguards for forest-dependent indigenous people, Kalasha. Besides, it encourages forest protection and reforestation. The measurement also includes logging ban targeted on large-scale commercial lumbering. Those measurements are effective but not sufficient, although the situation is improving according to the graph, to stop or averse deforestation a eclectic solution is needed, because we have to take economic factors into account. So regulations toward forest extraction for fuel-wood, and small-scale selective cutting were necessary. Since the wood-burning is a primary source of carbon emission, which leads to acid rain, the small-scale selective cutting can still be destructive toward forests. Given the fact that the procedures of the small-scale cutting is not standardize, it will hamper the recovery of the forest later. For example, the left uncleared timber pile will take up the space for new saplings to grow. 


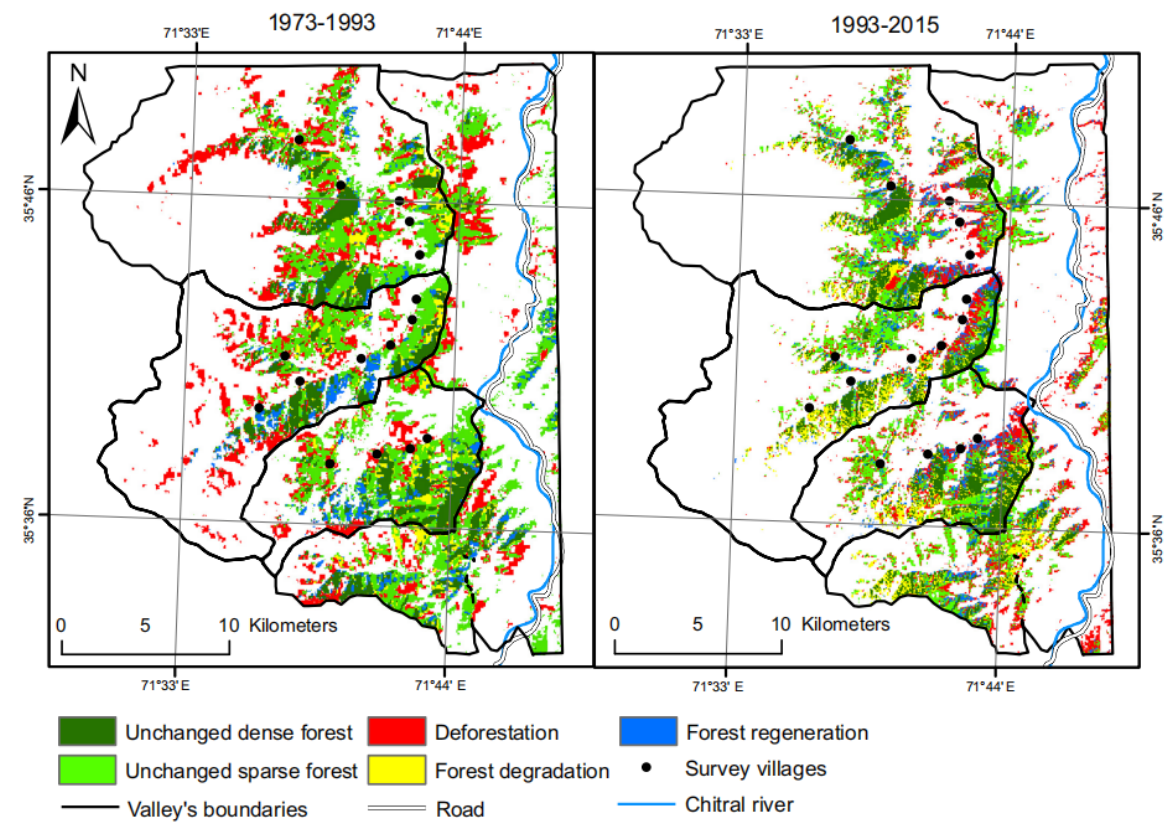

Figure 1. The study results of identifying local actors of deforestation and forest degradation in the Kalasha valleys of Pakistan-- existing forest restoration measurement has increased forest density

\subsection{The decline of bird community}

Another cause of increasing locusts plague was the shrinking of predatory bird community. As previously discussed, the intensified global warming and regional acid rain caused by increasing emission of carbon combined with human behavior resulted in deforestation, which means the loss of colonies for the birds in the forest. This drastically decreased the numbers of the predatory birds for locusts. Despite the terrible consequences, there are various reason for the government to choose not to employ vaccination.

Responses of 58 countries concerning why they had not or would not use avian influenza vaccines to control high-pathogenicity avian influenza or low-pathogenicity notifiable avian influenza

\begin{tabular}{|c|c|}
\hline Reasons for not using vaccines in avian influenza control & Responses \\
\hline Eradication is possible or has been successful using stamping out and other control measures & $24 \%$ \\
\hline Vaccination does not prevent infection and creates clinically silent shedcers & $22 \%$ \\
\hline Difficulty of differentiating the non-infected from infected birds in vaccinated populations (i.e. DIVA) & $17 \%$ \\
\hline High cost of vaccines and vaccination & $16 \%$ \\
\hline Vaccination would result in trade restrictions & $14 \%$ \\
\hline Lack of vaccination plan or policy & $9 \%$ \\
\hline No outbreaks or freedom from outbreaks & $5 \%$ \\
\hline Seven to 14 days are needed to induce an adequate level of immunological protection in a large poultry population & $5 \%$ \\
\hline Vaccination would mask detection of other avian influenza infections & $3 \%$ \\
\hline Vaccination in rural sector is difficult due to inability to trace movements of live poultry & $3 \%$ \\
\hline Vaccination promotes enzootic disease & $2 \%$ \\
\hline Vaccination results in increased laxity in biosecurity & $2 \%$ \\
\hline Vaccination is less efficient than depopulation & $2 \%$ \\
\hline Avian influenza outbreak only in low-density poultry production area & $2 \%$ \\
\hline
\end{tabular}

Figure 2. The study results of Assessment of national strategies for control of high-pathogenicity avian influenza and low-pathogenicity notifiable avian influenza in poultry, with emphasis on vaccines and vaccination-- reasons on why countries do not employ vaccination

Moreover, the bird population in Pakistan are not fully recovered from the Avian influenza H9N2 Virus. It is a high pathogenicity avian influenza which needed the government to add vaccination to the control programme instead of stamping-out only [2]. However, the vaccination coverage rate was far below average. What is more, the combination of $\mathrm{H} 5$ and $\mathrm{H} 7$ vaccination coverage was below $1 \%$. Not only was the treatment 
towards high pathogenicity insufficient, but also the monitor toward low pathogenicity was missing. The monitor toward low pathogenicity was essential since World Organization for Animal Health has already stated that there was genetic potential for the low pathogenicity

Responses of 58 countries concerning why they had not or would not use avian influenza vaccines to control high-pathogenicity
avian influenza or low-pathogenicity notifiable avian influenza

Figure 3. The study results of Assessment of national strategies for control of high-pathogenicity avian influenza and low-pathogenicity notifiable avian influenza in poultry, with emphasis on vaccines and vaccination-- number of doses of $\mathrm{H} 5$ and $\mathrm{H} 7$ avian influenza used in poultry against high-pathogenicity avian influenza and the coverage rate for 15 countries from 2002 to 2010

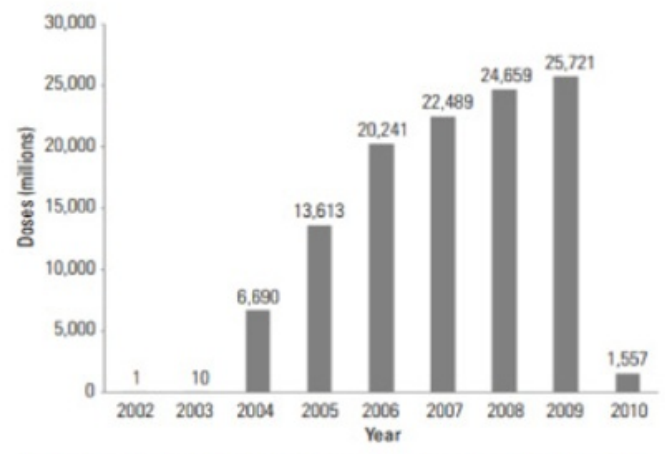

Number of doses of avian influenza vaccine used between 2002 and 2010 against high-pathogenicity avian influenza Data for China in 2010 were not available.

(1.43\%), all of which had enzootic H5N1 HPAl infections in poultry. The remaining 11 countries had minor usage, accounting for less than $0.7 \%$ in total, as follows:

Russia $(0.37 \%)$

- Pakistan $(0.12 \%)$

Hong Kong $(0.08 \%)$

Kazakhstan $(0.03 \%)$

Cote d'Ivoire $(<0.01 \%)$

DPR Korea $(<0.01 \%)$

France $(<0.01 \%)$

Israel $(<0.01 \%)$

Mongolia $(<0.01 \%)$

Figure 4. The study results of Assessment of national strategies for control of high-pathogenicity avian influenza and low-pathogenicity notifiable avian influenza in poultry, with emphasis on vaccines and vaccination--number of doses of avian influenza vaccination used between 2002 and 2010 against high-pathogenicity avian influenza 


\subsection{The increase of the temperatures}

Based on earlier discussion, deforestation has resulted many detrimental consequences including regional warming. We should not overlook the fact that mere temperature increase would also increase the numbers and accelerate the growth rate of the locusts. Studies have shown that the locusts have a self-destructive life styles when the temperature is abnormally high [3], they would gathered into huge groups, and prefer the temperature which they could maximize their growth rate and give up their efficient nutrient utilization since enzymes in locusts are no longer in the temperature where its bio-activity is in the peak. So this unusual behavioral changes of locusts could also be counted as an contributing factors for the increasing locusts plague

\section{Suggestions}

The causes of locusts plague in Pakistan have been identified. Based on the analysis above, the measurements implemented by government were not sufficient. The major objective for local government was to restore the forest as soon as possible. With increasing vegetation, locusts can be blocked, carbon emission can be decreased, and the number of predatory birds can be recovered. Local government should not only banned all kinds of logging but also encourage citizens to replant the woods. Despite the containment carried out by the government, civil and corporate actions could also play an important role in controlling locusts plague. Corporations can raise funds for the individuals who capture the most amounts of locusts and utilize those captured locusts into fodder supplement [5]. This way citizens and corporations can both gain economical benefits, and this environmental friendly measurement could decrease the use of pesticides [6]. Consequently, the balance of ecosystem can be restored sooner which also casts positive effects on the control of locusts plague.

\section{Conclusion}

According to the analysis, Pakistan's locusts plague is caused by a systematic environmental problem, which contains the collective effect of both the climate change and the improper activities of human. As a result, the solution to this problem is to find an environmental-friendly, sustainable, and inexpensive method to restore the forest without hampering economical development. In addition, other measurements such as planned conservation area to restored bird populations, painted quicklime powder on the remained wooded area to protect acid rains should be taken at instinct. This study was conducted during the pandemic so it is impossible to carry field research, so it can be improved by carrying field research in the future or obtaining more data to be applied to other countries.

\section{Acknowledgments}

Special thanks to professor André Dhondt and his inspiration

\section{References}

1. Zeb, A., Hamann, A., Armstrong, G. W., et al. (2019) Identifying local actors of deforestation and forest degradation in the Kalasha valleys of Pakistan. Forest Policy and Economics, 104: 56-64.

2. Swayne, D. E., Pavade, G., Hamilton, K., et al. (2011) Assessment of national strategies for control of high-pathogenicity avian influenza and low-pathogenicity notifiable avian influenza in poultry, with emphasis on vaccines and vaccination. Rev, Tech, 30(3): 839-870.

3. Cooper, B., Smith, J., Matheson, T., \& Ott, S. (2020). Plasticity of behavioural variability reflects conflicting selection in group-living and solitary desert locusts. 10.1101/2020.03.18.996983.

4. The economic times. (March 19, 2020) Pakistan's locust plague becomes as big as coronavirus. Retrieved from: https://m.economictimes.com/news/international/wo rld-news/pakistans-locust-plague-becomes-as-big-as -coronavirus/worst-locust-attack-in-decades/slidesho $\mathrm{w} / 74706969 . \mathrm{cms}$

5. Cai, Q., Hu, M. (2004) Integrated Utilization on Locusts Resource Realizing the Sustainable Control for the Plague of Locusts. Chinese Agricultural ence Bulletin.

6. Chang-Kan, L. I. (2001) Comprehensive prevention and control of the plague of locusts. Journal of Henan Education Institute. 